\section{AB0337 ASSESSMENT OF NUTRITIONAL STATUS IN WOMEN WITH RHEUMATOID ARTHRITIS MEASURED BY DUAL ENERGY X-RAY ABSORPTIOMETRY}

D. Reina ${ }^{1}$, C. Gómez Vaquero ${ }^{2}$, J.M. Nolla ${ }^{2} .{ }^{1}$ Rheumatology, Consorci Sanitari Integral; ${ }^{2}$ Rheumatology, Hospital Universitari de Bellvitge, barcelona, Spain

Background: As many other chronic diseases, rheumatoid arthritis (RA) has been related to an impairment of the nutritional status of multifactorial etiology. Even if Body Mass Index (BMI) has traditionally been used, it is not always a valid method, and there are still lots of questions without answer in how to evaluate ideally the nutritional status in these patients. Only very few studies had evaluated it by Dual Energy X Ray Absorptiometry (DXA).

Objectives: 1) To evaluate the nutritional status in women with RA and to compare with a population of same age women without RA using DXA for the analysis of whole body composition, 2) differences between the prevalence of alterations of the nutritional status measured by DXA and by the classical methods used in clinical care, 3) relation of RA time of evolution, inflammatory activity, physical function and dietary intake on altered nutritional status evaluated by DXA.

Methods: Case-control study including 89 patients that were diagnosed with RA and a control group (100) composed by patients affected by other non-inflammatory rheumatic diseases as soft tissue diseases. All the clinical charts were revised in order to record the following data: age, BMI, RA duration, history, activity and disability, serum albumin, Dietary intake, Whole body DXA assessment and Skeletal muscle index (SMI).

Results: Mean age of patients was $62 \pm 8$ years. Mean duration of RA was 13.7 \pm 9.3 years. Mean DAS28 was $3.7 \pm 1.4$ and mean Health Assessment Questionnaire was $0.88 \pm 0.77$. BMl of the patients was $27.43 \pm 5.16$ and $27.78 \pm 3.98$ in controls ( $p$ : ns). Albumin was within normal range in all patients.

RA patients presented a statistically significant lower lean mass than controls in all locations and lower fat mass in limbs, along with a higher fat trunk.

RA duration was found to be inversely correlated to BMI and lean mass and directly correlated with fat mass.

Neither BMI nor albumin correlated with DXA parameters.

RA patients fulfilled criteria of sarcopenia in $44 \%$ of de cases vs $19 \%$ of controls $(p<0,001)$. In RA patients, regarding SMI, BMI showed a high specificity to detect sarcopenia (94\% of the patients with low BMI had sarcopenia) but low sensitivity ( $47 \%$ of the patients with normal or overweight BMI had sarcopenia).

Conclusions: RA patients have an impairment of nutritional status associated to time of evolution that resembles sarcopenia and that is not predicted by BMI.

Disclosure of Interest: None declared

DOI: 10.1136/annrheumdis-2018-eular.5330

\section{AB0338 CLINICAL CHARACTERISTICS OF PATIENTS WITH RHEUMATOID ARTHRITIS WHO USED COMPUTER TERMINALS FOR SELF-ASSESSMENT OF DISEASE ACTIVITY AND QUALITY OF LIFE}

E. Pogozheva, V. Amirdzhanova. V. A. Nasonova Research Institute of Rheumatology, Moscow, Russian Federation

Objectives: To present the clinical features, pharmacotherapy, activity and quality of life in pts with rheumatoid arthritis (RA) who used computer terminals for selfassessment of pts with rheumatic diseases.

Methods: The study included 976 RA patients from the cohort of "TERMINAL" multicenter study, envisaging pts' self-assessment of disease activity and quality of life using a designated computer system ("Computer terminals for self-assessment of pts with rheumatic diseases) before the visit to the rheumatologist. Mean age $52,3 \pm 13,3$ years, mean disease duration $10,2 \pm 8,5$ years, $85 \%$ female. Baseline clinical parameters and pharmacotherapy were assessed, as well as disease activity (using DAS 28 and RAPID-3), and quality of life (using HAQ and EQ-5D). Results: $83 \%$ of pts were RF positive, and $60 \%$ ACCP positive. Almost all $(91,2 \%)$ pts received conventional DMARDs. $70,2 \%$ of them received methotrexate: $56,7 \% 15 \mathrm{mg} /$ week and $13,5 \%>15 \mathrm{mg} /$ week (from 17,5 to $40 \mathrm{mg} /$ week) $20,5 \%$ pts were treated earlier with low doses of glucocorticoids. $6,6 \%$ pts received Infliximab, 16,4\% - Rituximab and 9,8\% pts were treated with more than 1 biological agent in anamnesis. $46,2 \%$ of pts had high disease activity, $40,9 \%$ moderate, $4,5 \%$ low and $1,5 \%$ pts achieved clinical remission (mean DAS28 score $4,2 \pm 1,8$, RAPID $13,6 \pm 3,6$ ). Only $14,3 \%$ pts achieved general population HAQ values. The remaining showed significant reduction in the quality of life (mean HAQ $1,7 \pm 0,9, E Q-5 D 0,6 \pm 0,2) .7,4 \%$ of the pts had prosthetic joints.

Conclusions: In the studied population almost all patients were treated with DMARDs (mostly methotrexate), and about $30 \%$ received biological agents. High to moderate disease activity and reduction in quality of life were typical for this population. Persistence of disease activity and functional insufficiency in pts who received DMARD therapy may be explained by poor monitoring in real clinical practice. The introduction of computer system for self-assessment of disease activity and quality of life in the out-patient facilities will improve the interaction between doctors, nurses and patients, providing better control of therapy efficacy in RA patients.

Disclosure of Interest: None declared

DOI: 10.1136/annrheumdis-2018-eular.3256

\section{AB0339 SARCOPENIA AND EARLY FRAILTY SYNDROME IN RHEUMATOID ARTHRITIS}

E. Trujillo ${ }^{1}$, M.R. Garcia-Marrero ${ }^{2}$, M.I. Fuentes ${ }^{2}$, M.D.M. Trujillo ${ }^{3} .{ }^{1}$ Servicio de Reumatologia, Hospital Universitario de Canarias, la laguna; ${ }^{2}$ Gerencia de Atención Primaria, Tenerife; ${ }^{3}$ Funcanis, Fundación Canaria de Investigación, Canarias, Spain

Background: Sarcopenia and frailty are common in older persons and pose particular challenges for health and social care systems.

Sarcopenia, the loss of skeletal muscle mass, is a core component of physical frailty that together impact negatively on an individual's capability to live independently.

Frailty is defined as a syndrome of physiological decline in late life, characterised by marked vulnerability to adverse health outcomes. Frail adults are less able to adapt to stressors such as acute illness or trauma than non-frail adults. This increased vulnerability contributes to increased risk for multiple adverse outcomes, including procedural complications, falls, institutionalisation, disability, and death.

Rheumatoid arthritis (RA) is a chronic disabling disease, which leads to functional limitations and diminishes health-related quality of life. The presence of comorbidity and polypharmacy are both related to RA severity.

Objectives: The aim of this study was to assess the prevalence of sarcopenia and frailty syndrome in patients with RA.

Methods: Cross-sectional, observational and descriptive study in patients with RA (ACR criteria) older than 50 years.

Sarcopenia was defined as per the European Working Group on Sarcopenia in Older People definition as Skeletal muscle mass index (SMI) $\leq 8.87 \mathrm{~kg} / \mathrm{m}^{2}$ in men and $\leq 6.42 \mathrm{~kg} / \mathrm{m}^{2}$ in women. Body composition analysis was performed using bioelectrical impedance analysis (BIA)

Fragility was measured according to the 5 criteria proposed by Fried, using the Frail scale, and it was considered fragile to the patient who met at least 3 and prefragiles to those who met at least 2.

Frail scale: Based on five items, reflecting performance, selfreports and common co-morbidities (Morley JE et al. J Nutr Health Ageing 2012;16(7):601-8).

FRAIL SCALE

Did you feel worn out? or Did you feel tired?

Ability to climb one flight of stairs

Ability to walk $100 \mathrm{~m}$

Self-report of $>5 \%$ wt loss

$\leq 5$ of: dementia; heart Disease; depression; arthritis; asthma; bronchitis/emphy sema; diabetes; hypertension; osteoporosis; stroke.

Results: 283 consecutive RA patients were included, $83.4 \%$ ) were female. Mean age was 63.3 years and mean disease duration was 10.4 years.

Mean number of comorbidities was 1.48 , with systemic hypertension and obesity as the most frequent ones (33.8\% and $26.4 \%$, respectively). Polypharmacy was found in $96.8 \%$ and $64.7 \%$ received more than five drugs simultaneously.

$31 \%$ presented some degree of sarcopenia. $21.5 \%$ met frailty criteria $(42 \%$ in $\geq 65$ years old patients).

Conclusions: Prevalence of sarcopenia and frailty syndrome in this study was high. Rheumatologists should make an early detection of signs of frailty.

The screening and early detection of frailty can spur reforms to make routine care less hazardous, can focus on outcomes most relevant to patients and can aid in understanding effectiveness of health care interventions, including at the population level.

Disclosure of Interest: None declared

DOI: 10.1136/annrheumdis-2018-eular.3519

\section{AB0340 ASSOCIATION BETWEEN MICROALBUMINURIA AND METABOLIC SYNDROME IN PATIENTS WITH RHEUMATOID ARTHRITIS}

E. Baraka ${ }^{1}$, S. Abdel Moneim ${ }^{1}$, R. El Tanawy ${ }^{1}$, A. Shoshan ${ }^{1}$, Y. Ismail ${ }^{2}$.

${ }^{1}$ Rheumatology, Rehabilitation and Physical medicine; ${ }^{2}$ Clinical pathology, Benha Faculty of Medicine, Benha University, Cairo, Egypt

Background: Rheumatoid arthritis (RA) is an autoimmune, symmetrical polyarticular disease characterised by chronic inflammation of the synovial joints. Microalbuminuria (MA) occurs as a leakage of small amounts of albumin into the urine Metabolic syndrome (MetS) describes risk factors for cardiovascular diseases such as dyslipidaemia, obesity, hypertension and diabetes. 
Objectives: The aim of this study is to detect the prevalence of MA in patients with RA and study its correlation with disease activity and severity. Our aim extends to identify the association of MA with MetS in rheumatoid arthritis Methods: This study was carried out on 30 adult RA patients, 30\% male patients and $70 \%$ female patients (mean \pm SD $42.27 \pm 10.99$ years). Their mean disease duration was $12.8 \pm 7.06$ years. Twenty apparently healthy adults of matched age and sex served as a control group. All the patients were subjected to full history taking, full clinical examination, laboratory investigations and assessment of disease activity using DAS 28 Score. Urinary microalbumin level was measured in all subjects in early morning samples by the immunoturbidometry method. MetS was assessed in all subjects according to Grundy's criteria.

Results: The RA patients' group had highly significantly $(p<0.001)$ elevated mean values of urinary microalbumin and urinary albumin to creatinine ratio compared to the control group $(63.9 \pm 2.57 \mathrm{mg} / \mathrm{dl}$ vs $21.95 \pm 13.88 \mathrm{mg} / \mathrm{dl}, 46.6$ $\pm 35.28 \mathrm{ug} / \mathrm{mg}$ vs $14.9 \pm 11.45 \mathrm{ug} / \mathrm{mg}$ respectively).

The frequency of the metabolic syndrome according to Grundy's criteria was $60 \%$ in the RA patients' group. This frequency was highly statistically significant $(p<0.001)$ compared to the control group (10\%). The MetS was prevalent in 13/15 (87\%) of RA patients with microalbuminuria (MA), while 5 normo-albuminuric RA patients $(33 \%)$ had the MetS. A statistically significant difference was observed among these groups $(p<0.05)$. On the other hand, $13 / 18(72 \%)$ of RA patients with MetS had MA.

Although RA patients with MA had and increased mean values of disease duration, body mass index, waist circumference, fasting blood sugar, triglycerides, high density lipoprotein, DAS 28 and Larsen's score, they had no statistically significant differences compared to normo-albuminuric patients.

RA patients with the MA had a statistically significantly higher mean disease duration $(p=0.004)$ than patients without the MetS. There were highly statistically significant positive correlations $(p<0.001)$ of urinary microalbumin levels with disease duration, duration of morning stiffness, number of tender joints, number of swollen joints, ESR 1st hour, C-reactive protein, Larsen's score, DAS 28, and A/CR.

Conclusions: MA and MetS are frequent in RA, particularly in those with long standing disease. Early detection of albuminuria allows early intervention with the goal of reducing inflammation development in RA, CV risk. MetS is frequent in RA patients with MA

\section{REFERENCE:}

[1] Grundy SM, Cleeman JI, Daniels SR, Donato KA, Eckel RH, Franklin BA, et al. Diagnosis and management of the metabolic syndrome. An American Heart Association/National Heart, Lung, and Blood Institute Scientific Statement. Executive Summary. Circulation 2005;112:e285-e290.

Disclosure of Interest: None declared

DOI: 10.1136/annrheumdis-2018-eular.3423

\section{AB0341 METATARSOPHALANGEAL JOINTS HAVE MORE EROSIONS IN PATIENTS WITH RHEUMATOID ARTHRITIS}

M. Alagoz, E. Emlakcioglu ${ }^{1,2}$, A.C. Tunc ${ }^{3}$, on behalf of Meram Study Group, A. Kucuk ${ }^{2}$, on behalf of Meram Study Group, T. Gulen ${ }^{2}$, M. Kocabas ${ }^{2}$, R. Tunc ${ }^{2}$, on behalf of meram study group. ${ }^{1}$ Internal Medicine; ${ }^{2}$ Rheumatology, Meram Tip Fakültesi, Konya; ${ }^{3}$ Academy of Sports Science, Gazi University, Ankara, Turkey

Background: Rheumatoid arthritis (RA) is a chronic inflammatory disease characterised by destruction of synovial joints, especially in the hand and feet, leading to severe disability and premature mortality. The erosions seen in RA differentiate it from other rheumatological diseases.

Objectives: The aim of the study was to evaluate the relationship between attack frequency and erosions seen in RA.

Methods: Forty-four patients according to 2010 ACR/EULAR Classification Criteria for RA were included into the study. Involved joints and number of attacks were recorded. The X-rays of the involved joints were assessed on admission and after 3 months in terms of joint erosion as a blinded manner. Comparison of erosions were calculated by chi-square.

Results: Kappa value of intra-observer agreement of reading of x-ray films was 0.68. Erosions were detected in 16 of 44 patients with RA. The Ratios of erosion in joints with more than 10 attacks were different according to involved joints. The ratios of erosions were $10 \%$ for metacarpophalangeal (MCP), $8 \%$ for proximal interphalangeal (PIP), $0 \%$ for knee, $5 \%$ for ankle and $69 \%$ for metatarsophalangeal (MTP) joints. When compared MTP joints with MCP, PIP and wrist joints, it was seen that the erosion rate was higher in MTP joints than the other joints $(p<0,01)$. Knee and ankle joints were combined as a single group and compared with MTP joints in terms of erosion. It was seen that the erosions in the MTP joints were significantly higher than the erosions in the knee and ankle joints $(p<0,01)$ Conclusions: In RA, the erosion ratio of MTP joints was significantly higher than seen in MCP, PIP and wrist joints. On the other hand the erosion rate in knee and ankle joints was rare. These results show us the erosion in MTP joints may not related to mechanical overload. Therefore foot imaging with $\mathrm{x}$-ray may be important in the following of patients with RA. In addition existence of false positive erosions in MTP joints of healthy people should be studied.

Disclosure of Interest: None declared

DOI: 10.1136/annrheumdis-2018-eular.6954

\section{AB0342 THE CHRONIC HAND PAIN IN RHEUMATOID ARTHRITIS, OSTEOARTHRITIS, AND FIBROMYALGIA: THE ROLE OF CENTRAL SENSITISATION}

F.F. Ayhan ${ }^{1,2}$, M.A. Güler ${ }^{1}$, Ö. F. Çelik ${ }^{1} .{ }^{1}$ Department of Physical Medicine and Rehabilitation, Divisions of Rheumatology, Pain Medicine, Health Science University, Ankara Health Research and Training Hospital, Ankara; ${ }^{2}$ Department of Physical Therapy and Rehabilitation, Usak University, High School of Health Sciences, Usak, Turkey

Background: Modern pain medicine divided chronic pain as nociceptive, neuropathic, central sensitisation (CS) and mixed pain. CS syndromes are a group of disorders characterised by chronic non-neuropathic and non-nociceptive pain(. ${ }^{1}$ Central sensitisation inventory (CSI) suggest the tool generates reliable and valid data that quantify the severity of several symptoms of $\mathrm{CS}^{2}{ }^{2}$

Objectives: Hand pain in RA, OA, and FMS have different features. The aim of this study was to show the role of CS pain in these patients.

Methods: Totally 151 patients with chronic hand pain (56 RA, $45 \mathrm{OA}$, and 50 FMS) were included. CSI was used for evaluation of CS. ${ }^{2,3} \mathrm{CSI}$ consists of 2 parts: CSI-A scoring 0-100 and CSI-B including 10-CS related syndromes (restless leg, chronic fatigue, fibromyalgia, temporomandibular disorders, migraine/tension type headache, irritable bowel, multiple chemical sensitivity, whiplash, anxiety/ panic attack, and depression)

Results: Sixteen patients $(28.57 \%)$ had active (DAS28 $\geq 2.6)$ RA. Disease activity was not related with CSI-A and CSI-B scores. Rheumatoid hands was less painful compared with them of OA and FMS $(p<0.001)$. The CS pain was detected in most of the patients with FMS, compared with OA and RA patients $(p<0.001)$ Similarly, CSI-A score was the highest in patients with FMS group $(p<0.001)$ and similar in both OA and RA groups $(p>0.05)$. CS-related syndromes were also detected in both RA and OA groups, but less than FMS group $(p<0.005)$. The numbers of CS syndromes were similar in both RA and FMS $(p=0.084)$ and higher than OA group $(p=0.036)$. Table 1 shows the demographic and pain parameters in all groups. CSI-A score was correlated with VAS-pain score $(r=0.364, p<0.001)$.

\begin{tabular}{lccccc}
\multicolumn{7}{l}{ Abstract AB0342 - Table 1. The comparisons of groups } \\
\hline & $\mathbf{1 . R A}$ & $\mathbf{2 . 0 A}$ & $\mathbf{3 . F M S}$ & $\mathbf{P 1 - 3}$ & P2-3 \\
\hline Age(mean \pm SD) & 54.52 & 61.2 & $45.22 \pm 8.6$ & 0000 & 0000 \\
& $\pm 10,33$ & \pm 9.67 & & & \\
Female\% & $\% 83.92$ & $\% 88.88$ & $\% 94$ & 0.564 & 0370 \\
DAS28 & $2.21 \pm 0.66$ & & & & \\
VAS & $4.09 \pm 2,27$ & 6.78 & $8.00 \pm 1.8$ & 0000 & 0001 \\
& & \pm 1.70 & & & \\
CSI-A (+)\% & $\% 41.07$ & $\% 62.22$ & $\% 94$ & 0000 & 0000 \\
CSI-A & $38.43 \pm 16.2$ & 43.6 & 58.92 & 0000 & 0000 \\
& & \pm 13.1 & \pm 14.78 & & \\
CSI-B (+)\% & $\% 60$ & $\% 28.88$ & $\% 100$ & 0000 & 0000 \\
CSI-B & $1.30 \pm 1.6$ & 0.51 & $1.98 \pm 1.2$ & 0000 & 0000 \\
& & \pm 1.05 & & & \\
Restless leg & $\% 19.64$ & $\% 4.44$ & $\% 8$ & 0101 & 0477 \\
Chronic fatigue & $\% 16.07$ & $\% 2.22$ & $\% 6$ & 0131 & 0360 \\
Fibromyalgia & $\% 14.28$ & $\% 2.22$ & $\% 100$ & 0000 & 0000 \\
TMD & $\% 23.21$ & $\% 17.77$ & $\% 0$ & 0000 & 0132 \\
Migraine/TTH & $\% 12.5$ & $\% 2.22$ & $\% 30$ & 0032 & 0231 \\
İritable bowel & $\% 5,3$ & $\% 2.22$ & $\% 4$ & 0742 & 0621 \\
Multi-chemical & $\% 3,57$ & $\% 0$ & $\% 4$ & 0908 & 0175 \\
S. & $\% 1.14$ & $\% 0$ & $\% 2$ & 0212 & 0340 \\
Whiplash injury & $\% 10.71$ & $\% 2.22$ & $\% 18$ & 0403 & 0030 \\
Anxiety/panic & $\% 16.07$ & $\% 15.55$ & $\% 28$ & 0161 & 0215 \\
Depression & & & & &
\end{tabular}

Conclusions: Central sensitisation should be considered in patients with chronic persistent pain, not only having FMS, but also half of the patients having RA and $\mathrm{OA}$. It is not a rare phenomenon and if it is exists, effective pain management strategies could be needed in addition to the specific pharmacologic treatment.

\section{REFERENCES:}

[1] O'Leary H, et al. Nervous System Sensitization as a Predictor of Outcome in the Treatment of Peripheral Musculoskeletal Conditions: Pain Pract 2017;17(2):249-266.

[2] Neblett R, et al. The CSI. The Journal of Pain 2013;14(5):438-45. 